\title{
Ocorrência do gênero Dolyobius Linnavuori (Hemiptera, Cicadellidae) no Brasil e descrição do macho de Dolyobius distinctus Linnavuori ${ }^{1}$
}

Occurrence of Dolyobius Linnavuori (Hemiptera, Cicadellidae) in Brasil and description of the male of Dolyobius distinctus Linnavuori ${ }^{1}$

$$
\text { Keti Maria Rocha Zanol }{ }^{2}
$$

LinNAVUORI (1959) descreveu o gênero Dolyobius com duas espécies: Dolyobius lingulatus (Equador) e Dolyobius distinctus (Paraguai); este baseado em exemplares fêmeas.

O gênero caracteriza-se por apresentar a coroa levemente mais longa medianamente do que junto aos olhos; região frontal microesculturada; região discal lisa; ocelos na margem anterior, levemente visíveis de cima; sutura coronal alcançando a metade do comprimento da coroa; genas sinuosas. Asas anteriores transparentes, com duas células anteapicais; apêndices distintos. Espinulação das tíbias anteriores $1+4$ e dos fêmures posteriores $2+2+1$. Pigóforo com apêndices. Valva genital triangular. Placas subgenitais triangulares; macrocerdas unisseriadas. Edeago simétrico; gonóporo apical. Sétimo esterno, da fêmea, com lobo mediano.

${ }^{1}$ Contribuição ${ }^{\circ} 1247$ do Depto de Zoologia, Setor de Ciências Biológicas, UFPR. Professor Adjunto do Depto. de Zoologia, Setor de Ciências Biológicas, UFPR — Caixa Postal 19020 - 81531-980 Curitiba, Paraná, Brasil e Bolsista de CNpq. 
O material estudado pertence as seguintes Instituições: American Museum of Natural History, Nova Iorque, EUA (Coleção Rauno Linnavuori-AMNH), Museo Nacional de Historia Natural, Assunção, Paraguai (MHNP) e Coleção de Entomologia Pe J. S. Moure, Departamento de Zoologia, UFPR, Curitiba, Brasil (DZUP).

\section{Dolyobius distinctus Linnavuori, 1959}

(Figs. 1-7)

МАCHO

Semelhante à fêmea. Coroa amarelada com oito manchas marrom-escuras: seis manchas arredondadas sendo quatro na margem anterior e duas sobre o disco; e duas manchas, em forma de L invertido, laterais à sutura coronal. Frontoclípeo marrom-escuro com uma faixa longitudinal e cinco pares de arcos laterais amarelos. Anteclípeo marrom-escuro. Lora e genas amarelas.

Pronoto marrom-claro; margem basal com manchas marromescuras e marfim. Asas anteriores marrom-claras; clavo e ápice marrons. Venação amarela.

Pigóforo com um par de apêndices apicais, espiniformes, voltados para dentro e para cima. Estilos com apófises curvas para fora. Edeago sem apêndices; ápice, em vista lateral, imbricado.

FÊMEA

Sétimo esterno com a margem posterior fortemente escavada e com pequeno lobo mediano com uma reentrância no meio.

Comprimento total — Macho: 4,00 mm; fêmea: 4,04 mm.

Material eXAminado - PARAGUAI. Todo Cué, typus Dolyobius distinctus LV (AMNH); Canyndyú: 11-17.IV.1996, A. C. F. Costa leg.? Reserva Natural del Bosque Mbaracayú, 1 fêmea (MHNP). BRASIL. Bahia: Encruzilhada, IX. 1975, M. Alvarenga leg., 1 macho, 1 fêmea; Goiás: Aragarças, 29.III.1963, M. Alvarenga leg. 3 machos; São Paulo: Botucatu, 5.I.1973, M. Menezes leg., 1 macho (DZUP).

VARIAÇÃO INTRA-ESPECÍFICA

Pode ocorrer uma veia extranumerária entre 1A e a sutura claval. 


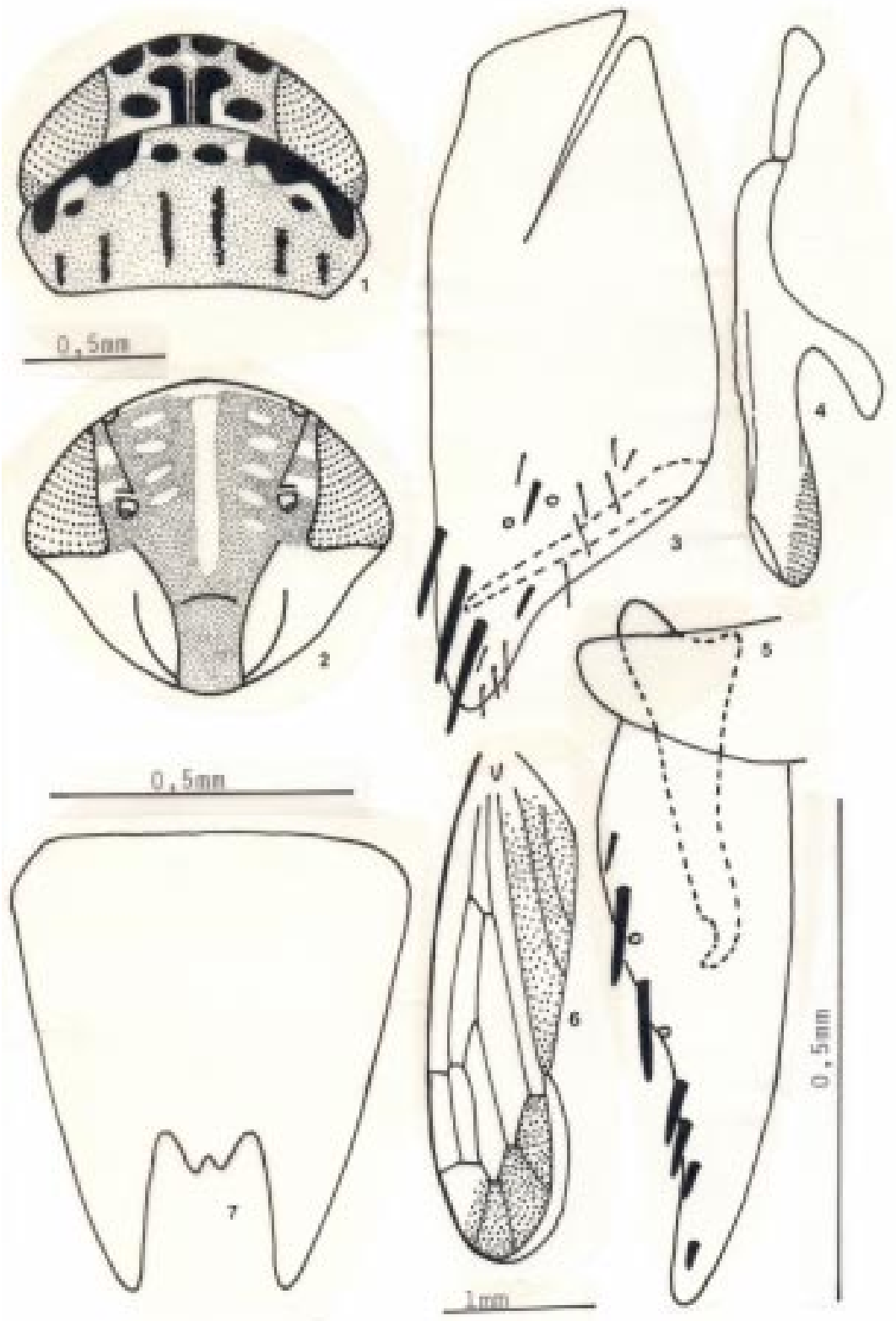

Figs 1 a 7. Dolyobius distinctus Linnavuori. 1, cabeça e pronoto, dorsal; 2, face; 3, pigóforo, lateral; 4 , conetivo e edeago, lateral; 5 , valva genital, estilo e placa subgenital; 6 , asa anterior; 7 , sétimo esterno da fêmea. 


\section{RESUMO}

O macho de Dolyobius distinctus Linnavuori, 1959 é descrito, sendo a primeira ocorrência do gênero no Brasil.

Palavras Chave: Cicadellidae, Deltocephalinae, Dolyobius, Hemiptera

\section{SUMMARY}

The male of Dolyobius distinctus Linnavuori, 1959 is described and this genus is reported for the first time in Brazil.

Key words: Cicadellidae, Deltocephalinae, Dolyobius, Hemiptera

\section{RÉSUMÉ}

Le mâle de Dolyobius distinctus Linnavuori, 1959 est décrit et ce genre est rapporté pour la première fois au Brésil.

Mots clés: Cicadellidae, Deltocephalinae, Dolyobius, Hemiptera

Recebido em: 2.05.2003. 